\title{
Ambient fine particulate matter pollution over the megacity Delhi, India: an impact of COVID-19 lockdown
}

\author{
M. Arunkumar* and S. Dhanakumar \\ PG and Research Department of Environmental Science, PSG College of Arts and Science, Coimbatore 641 014, India
}

In this study, we investigate the impact of the COVID19 pandemic on $\mathbf{P M}_{2.5}$ levels in the national capital city Delhi, India. $\mathbf{P M}_{2.5}$ and meteorological data from 35 ground-based monitoring stations over Delhi city are utilized for the present study. Geographic Information System-based spatial interpolation method was employed to analyse the spatial pattern of $\mathbf{P M}_{2.5}$ from January to April 2020 and compared with that of preceding years (2018-19). The findings indicate that the $\mathbf{P M}_{2.5}$ level has reduced significantly during the lockdown period. About $40 \%$ of reduction in $\mathbf{P M}_{2.5}$ concentrations is observed when compared to the prelockdown phase. Exclusively between 25 March and 30 April, about $94.44 \%$ of days were within the NAAQS 24-h standard limit of $60 \mu \mathrm{g} / \mathrm{m}^{3}$. The significant role of meteorology in the dispersal of $\mathrm{PM}_{2.5}$ over Delhi is clear from the correlation analysis. A strong negative correlation $(r=-\mathbf{0 . 5 4 6})$ between the Temp and $\mathbf{P M}_{2.5}$ indicates the better dispersion of air pollutants during high-temperature conditions. A higher reduction in $\mathbf{P M}_{2.5}$ has been observed in Central, Northern and Eastern parts of the megacity. The present study provides insights to policymakers to prepare and implement future policy measures for controlling air pollution levels in the megacity.

Keywords: Air pollution, COVID-19, lockdown, particulate matter.

\section{Introduction}

AIR pollution is recognized as the most critical environmental issue worldwide and is the top environmental risk factor for human health. The World Health Organization (WHO) reported that about 4.2 million mortalities occurred in 2016 due to ambient air pollution. Moreover, air pollution has attributed to $26 \%$ of respiratory infection deaths, $25 \%$ of chronic obstructive pulmonary disease deaths and about $17 \%$ of ischaemic heart disease and stroke $^{1}$. Currently, Indian cities are among the most polluted areas in the world, and ambient fine particulate matter $\left(\mathrm{PM}_{2.5}\right)$ pollution is the most severe environmental problem in India ${ }^{2}$. Even though several mitigation measures

\footnotetext{
*For correspondence. (e-mail: m.arunkumarmail@gmail.com)
}

are implemented, only partial enhancement in air quality has been seen in Indian cities. Also, $\mathrm{PM}_{2.5}$ pollution is expected to worsen in the coming years due to rapid ongoing urbanization ${ }^{3}$. A decline in air pollution levels has been observed and reported in most of the developed cities as a result of curfews and restricted movement in the wake of the COVID-19 pandemic ${ }^{4}$.

The COVID-19 originated in December 2019 in China, spread rapidly to all other countries within a few months, and turned out to be a potential health catastrophe. In India, the first case of COVID-19 was recorded on 30 January 2020. Since then, the number of cases has increased steadily and significantly. As of 7 November 2020 , a total of $84,62,080$ confirmed cases and 125,562 deaths have been registered across Indian states ${ }^{5}$. It is well known that long-term exposure to high levels of air pollutants will directly affect the respiratory system, and in the present condition, high air pollution and smoking will make people more vulnerable to the coronavirus disease. Moreover, daily COVID-19 infections are positively correlated with $\mathrm{PM}_{2.5}$ concentration ${ }^{6}$, and just a $1 \mu \mathrm{g} / \mathrm{m}^{3}$ increase in $\mathrm{PM}_{2.5}$ may be corresponding to $8 \%$ [CI: 2-15\%] of the increase in COVID-19 deaths ${ }^{7}$. Air pollution is expected to be the deciding factor of coronavirus-related deaths in severely affected countries ${ }^{8}$. To control the spread of the virus, the government of India announced a three-week-long nationwide lockdown starting 25 March 2020. This action put almost all non-essential services and businesses, major industrial and commercial activities on hold across the country, and all means of transport have been stopped. However, due to the rapid spread of the COVID-19 virus, the lockdown was further extended up to 17 May across the country. The associated reduction in traffic and industry has socio-economic and environmental impacts, which are yet to be quantified. Interestingly, halting industrial operations and vehicles movement during the lockdown has led to a reduction in air pollution from severe to moderate in most parts of the world.

Delhi is the capital of India and one of the most developed and inhabited cities, which is located in Northern India. Delhi is the largest urban agglomeration in India, with a population of 1.68 crores displaying a decadal growth rate of $21 \%$ and a density of 11,297 persons per square kilometre ${ }^{9}$. National Capital Territory (NCT) 
Delhi located between $28^{\circ} 24^{\prime} 17^{\prime \prime} \mathrm{N}$ to $28^{\circ} 53^{\prime} 00^{\prime \prime} \mathrm{N}$ and $76^{\circ} 50^{\prime} 24^{\prime \prime} \mathrm{E}$ to $77^{\circ} 20^{\prime} 37^{\prime \prime} \mathrm{E}$, occupies about $1485 \mathrm{~km}^{2}$ $\operatorname{area}^{10}$. As of March 2018, the total number of motor vehicles in the NCT Delhi was 109.86 lakh, showing a $5.81 \%$ growth from the previous year. The number of vehicles per thousand people increased to 598 in $2017-$ 18. Two-wheelers contribute approximately $64.43 \%$ of the total vehicle population ${ }^{11}$. Rapid urbanization, along with growing population and vehicle numbers, makes Delhi's air quality more harmful. According to WHO, New Delhi is the world's worst polluted city in 2016 in terms of $\mathrm{PM}_{10}$ and $\mathrm{PM}_{2.5}$. It was estimated that about 147 tonnes of particulate matter were emitted per day in Delhi city, in which about $52.5 \%$ was contributed by road dust, followed by industries $(22.1 \%)$ and residential sources $(18.8 \%)^{12}$. Delhi is reported to have 29 planned industrial areas and 5 factory centres ${ }^{10}$. To tackle the very high pollution levels in Delhi, three-wheelers and the bus fleet were converted from petrol/diesel to Compressed Natural Gas (CNG), and metro rail and fly-overs have been constructed in the past decade. The National Green Tribunal (NGT) banned old diesel vehicles (10 years or older) from operating in the city. A 15-day odd-even vehicle rule applied between 1 and 15 January 2016 and the same between 15 and 30 April 2016 for personal diesel and petrol cars, wherein odd and even-numbered cars were allowed to operate on alternate days ${ }^{12-14}$. However, the overall increase in the number of vehicles and other urban emission sources has rapidly receded the anticipated traffic emission reductions, and pollution over the Delhi city exhibited unceasing growth ${ }^{15}$. Recent satellite-based observations show a dramatic drop in air contaminants in extremely polluted metropolises since imposing the lockdowns ${ }^{8}$.

In the present study, we evaluate the impact of COVID-19 lockdown on $\mathrm{PM}_{2.5}$ pollution in the Delhi metropolitan based on the ground observations. A geospatial tool (IDW), is applied to fill the monitoring gaps for better visualization of $\mathrm{PM}_{2.5}$ pollution. Besides, the influences of local meteorological characteristics have been taken into account to understand the underlying factors affecting the concentration levels of $\mathrm{PM}_{2.5}$ during the shutdown period. We also examine the effect of lockdown on the daily concentrations of $\mathrm{PM}_{2.5}$ of the last four months from January to April 2020, in comparison with the previous years (2018-2019).

\section{Methodology}

\section{Data collection}

In Delhi city, a total of 37 air quality monitoring stations are maintained by the Central Pollution Control Board, Delhi Pollution Control Committee (DPCC), and the Indian Institute of Tropical Meteorology, Pune. Most of these stations monitor criteria air pollutants (sulphur dioxide, nitrogen dioxide, carbon monoxide, particulate matter, ozone and lead) continuously along with meteorological parameters. Monitoring data is accessible to both public/institutional bodies and individuals. Daily average monitoring data for $\mathrm{PM}_{2.5}$ and meteorological parameters (temperature, wind speed and relative humidity) for January-April 2018, 2019 and 2020 were obtained from CPCB online portal for air quality data dissemination (https://app.cpcbccr.com/ccr/\#/caaqm-dashboard-all/ caaqm-landing) ${ }^{16} \cdot \mathrm{PM}_{2.5}$ was measured based on the $\beta$-ray attenuation technique in which particulate matter was sampled through the instrument and collected on fiberglass filter tape. $\beta$-ray radiation is measured before and after sampling by scintillation or Geiger-Muller coun$\operatorname{ter}^{17}$. The lower detection limit of monitors is $0.1 \mu \mathrm{g} / \mathrm{m}^{3}$. Operating bodies frequently standardize the monitors as per the equipment manual for verifying the quality of the data $^{18,19}$. Daily mean concentration from 35 monitoring stations of NCT Delhi was utilized to calculate a valid aggregated value (city-level 24-hour average concentration) and subsequent calculations. Some missing data were observed in the continuous times series data, which were discarded from the analysis. We used daily average concentrations to match with the meteorological factors, which also used daily average measurements.

\section{Statistical analysis}

The data obtained were statistically treated using the program SPSS version 21.0 and data analysis tool from Microsoft excel-2016. Descriptive statistics and frequency analysis were used to explain daily and monthly trends of $\mathrm{PM}_{2.5}$ and other meteorological parameters. The Pearson correlation test was used to determine the correlation between $\mathrm{PM}_{2.5}$ and meteorological factors. To detect and estimate the changes within the time-series and quantify the lockdown effect on air pollutant levels, the study period was subdivided into two groups, namely prelockdown (1 March 2020 to 24 March 2020) and lockdown period (25 March 2020 to 30 April 2020). The legislative measures issued by the Government of India were taken into account for this grouping. During the lockdown period (21 days), since 25 March 2020, stringent measures forced to close all industrial operations, ban on transportation, and public movement was limited only to essential needs ${ }^{20}$. In the period of post-lockdown, schools and universities were closed, public transport entirely constrained, whereas industries, private transport, and commercial sectors such as hotels and shops were allowed to operate with partial restrictions ${ }^{21}$. The deviations in the pollutant concentrations were computed by calculating the relative variation (in \%) and the difference in the mean concentration (in $\mu \mathrm{g} / \mathrm{m}^{3}$ ) during the lockdown compared to the pre-lockdown period. 


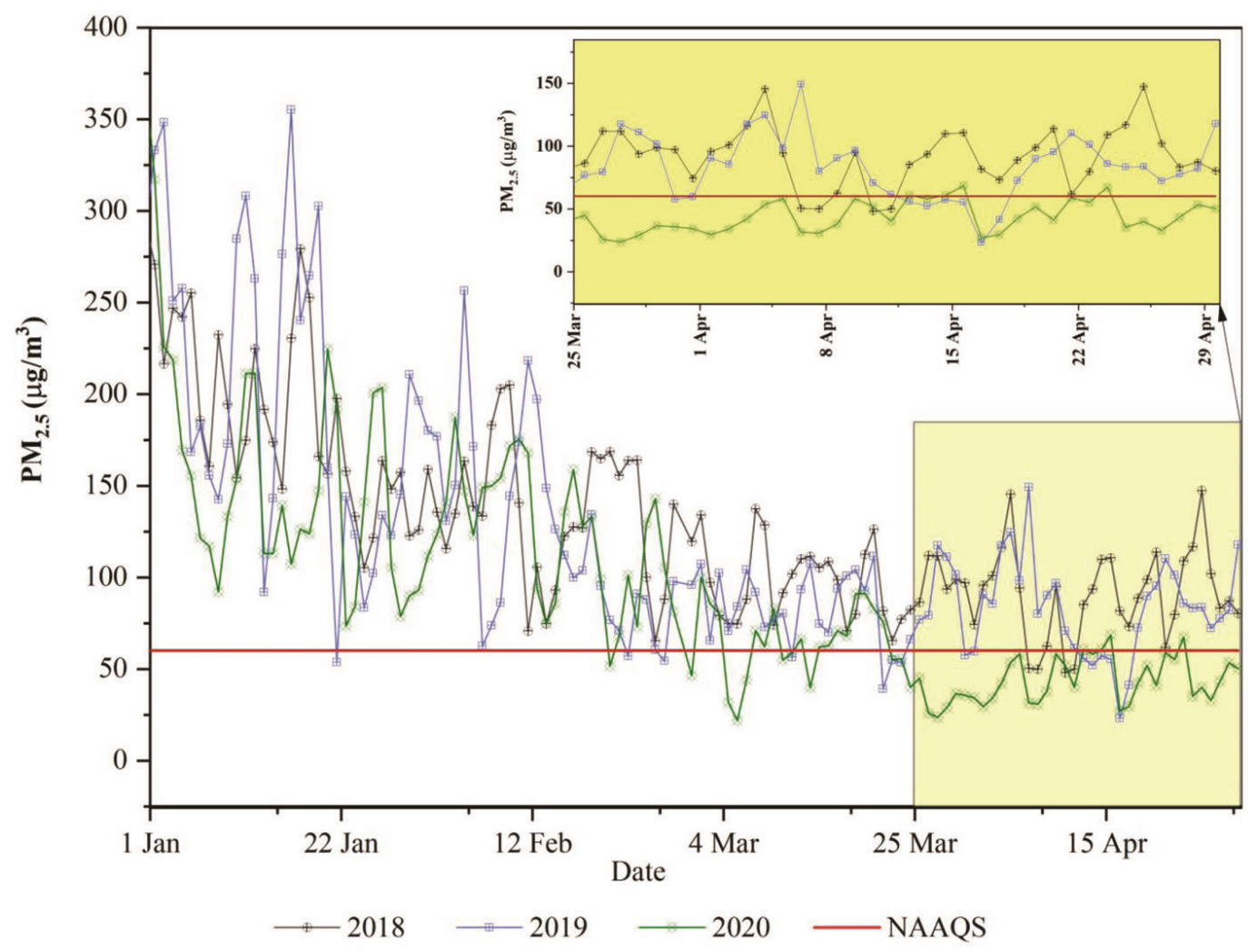

Figure 1. Daily variations in ambient fine particulate matter in Delhi city during the study period. Inset shows the $\mathrm{PM}_{2.5}$ from 25 March 2020 to 30 April 2020 for the years 2018, 2019 and 2020, accordingly.

\section{Inverse distance weighting}

The interpolation technique with the geographical information system (GIS) software was applied to interpolate the air quality data to determine the pollutant distribution. Spatial interpolation was the most convenient and timeefficient method to estimate $\mathrm{PM}_{2.5}$ distribution. Several studies showed that the visualization of $\mathrm{PM}_{2.5}$ concentrations over the study area could be best achieved using inverse distance weighting (IDW). The correlation coefficient between simulated and observed values was higher for IDW than the other techniques, such as kriging and spline $^{22,23}$. The IDW methodology assumes that the concentrations at a specific site are more affected by proximate rather than distant sites. To predict a value at unmonitored sites, IDW uses the available concentrations at the neighbouring sites. Compared with other methods, the IDW method is simpler to program and does not require pre-modelling or subjective assumptions in selecting a semi-variogram model. For the study area, the spatial data was first created within a GIS environment using ArcGIS Pro 2.4.1 (Trial version). The monthly mean concentrations of $\mathrm{PM}_{2.5}$ data from 35 monitoring locations were used for the interpretation of $\mathrm{PM}_{2.5}$ distribution within the Delhi city. Based on these monitoring locations, the interpolated maps were generated for the period January-April 2020 and compared with the same period averaged over the past two years (2018-2019), representing baseline conditions.

\section{Results and discussion}

\section{Daily fine particulate matter trend}

The present study analyses $\mathrm{PM}_{2.5}$ data collected from air quality monitoring stations in Delhi city to determine the impact of city lockdown on $\mathrm{PM}_{2.5}$ pollution. The panel of Figure 1 presents the daily trend of $\mathrm{PM}_{2.5}$ in Delhi city from 1 January to 30 April. A solid red line in Figure 1 represents the 24-hour National Ambient Air Quality Standard prescribed by the Central Pollution Control Board, India ${ }^{24}$. $\mathrm{PM}_{2.5}$ concentrations follow a parallel trend during the study period (2018, 2019 and 2020), which starts deteriorating just at the end of the winter season and reaches the lowest during April. Slightly lower concentrations of fine PM were observed throughout January-April 2020, relative to the same period in 2018 and 2019. Most importantly, a drastic reduction in $\mathrm{PM}_{2.5}$ levels has been observed just within a few days of lockdown enforcement.

For a better understanding of the daily trend, the $\mathrm{PM}_{2.5}$ concentration is classified as follows: Safe (less than $60 \mu \mathrm{g} / \mathrm{m}^{3}$ ), moderate $\left(60-120 \mu \mathrm{g} / \mathrm{m}^{3}\right.$ ) and poor (greater 

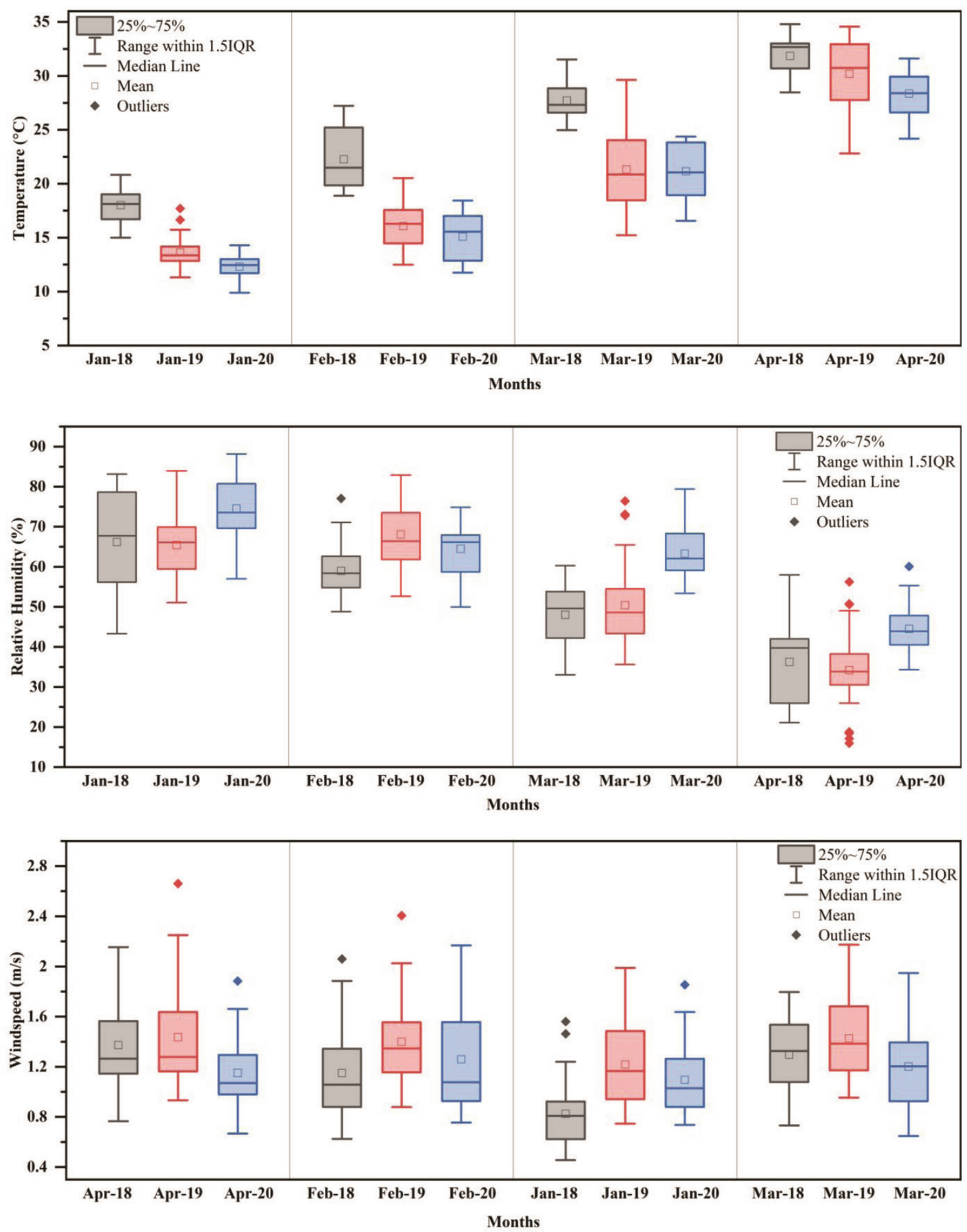

Figure 2. Monthly variations in meteorological parameters (temperature, relative humidity and wind speed) in Delhi city during 2018, 2019 and 2020.

than $120 \mu \mathrm{g} / \mathrm{m}^{3}$ ). The number of poorly polluted days reduced to $30.83 \%$ in 2020 , compared to $35 \%$ in 2019 and $46.67 \%$ in 2018 . Furthermore, the percentage of days classified as safe increased to $35.83 \%$ against $12.5 \%$ CURRENT SCIENCE, VOL. 120, NO. 2, 25 JANUARY 2021
(2019) and 3.33\% (2018) in the preceding years. Between 25 March to 30 April 2020 (lockdown period), about $94.44 \%$ of days were within the safety standard limits. The remaining days were moderately polluted. This is a 
vibrant indication that lockdown has resulted in control of $\mathrm{PM}_{2.5}$ pollution. There may be two reasons for the reduction in the concentrations of $\mathrm{PM}_{2.5}$ during the study period. First, the rise in temperature from January to April was more favourable to the dispersion of pollutants. Next, the implementation of lockdown and control measures leads to closure of industries and ban on both public and private vehicle movement, considering that automobile and industrial emissions are prime sources of $\mathrm{PM}_{2.5}$ in Delhi city ${ }^{25}$. Similar kinds of observations were recorded when the odd-even car trial scheme was implemented in 2016, in which PM concentrations reduced by about $74 \%$ during trail hours ${ }^{12}$. These reductions were more likely due to traffic elimination since the sum of road dust, and vehicle emissions contribute about $58 \%$ of the $\mathrm{PM}_{2.5}$ emissions in Delhi ${ }^{26}$.

\section{Influence of meteorological parameters on $P M_{2.5}$}

Meteorology is a major factor in ambient PM concentrations since dispersion processes, removal mechanisms and chemical formation of atmospheric particles depend on meteorological parameters. Statistical summary of the ambient temperature (Temp), relative humidity $(\mathrm{RH})$ and wind speed (WS) from January to April in 2018, 2019 and 2020 is shown in Figure 2. As expected, during the winter months (January and February), the mean Temp was lower than that of March and April. The maximum recorded Temp was $31.86 \pm 1.72$ and $30.20 \pm 3.18^{\circ} \mathrm{C}$ (in April). In contrast, the minimum Temp recorded to be $18.01 \pm 1.48$ and $13.63 \pm 1.42^{\circ} \mathrm{C}$ (in February) for 2018 and 2019 respectively. Likewise, maximum $\left(28.36^{\circ} \mathrm{C}\right)$ and minimum $\left(12.31^{\circ} \mathrm{C}\right)$ temperature was recorded between January and April 2020. With regard to interannual variations, the mean Temp was found to be lower in both the winter and summer season of 2020 compared with the same time scale in 2018 and 2019. In contrast,

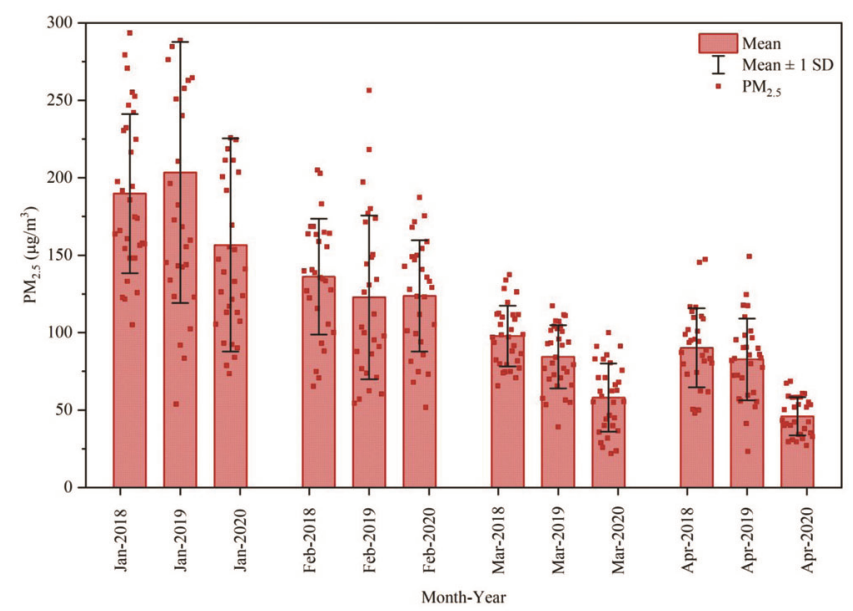

Figure 3. Monthly mean concentrations and variations of $\mathrm{PM}_{2.5}$ in NCT Delhi.
RH increased from $66.14 \%$ (2018) and $65.39 \%$ (2019) to $74.56 \%$ (2020) for January and $36.25 \%$ (2018) and $34.19 \%$ (2019) to $44.49 \%$ in April. With regard to WS, significant variations existed between the years. In January, the WS ranged from 0.67 to 1.88 and 0.75 to $1.99 \mathrm{~m} / \mathrm{s}$, with the mean of 1.15 and $1.22 \mathrm{~m} / \mathrm{s}$ for 2018 and 2019 respectively, whereas it varied between 0.75 and $1.85 \mathrm{~m} / \mathrm{s}$, with an average of $1.10 \mathrm{~m} / \mathrm{s}$ in January 2020. Likewise, the mean WS in April recorded 1.37, 1.44 and $1.15 \mathrm{~m} / \mathrm{s}$ for 2018, 2019 and 2020 respectively.

Wang et al. ${ }^{27}$ reported that the lockdown in China did not result in significant improvement in air quality due to unfavourable meteorology. Hence, correlation analysis considering daily averaged $\mathrm{PM}_{2.5}$ and meteorological parameters in 2020 was performed to determine the influence of climate variables on $\mathrm{PM}_{2.5}$ concentrations. The relationship between the study variables, along with Pearson's correlation coefficient, is given in Table 1. The variability of correlations depicts the influence of meteorological parameters such as Temp, WS and RH on pollution dispersal. These results showed that all three meteorological parameters significantly correlated with $\mathrm{PM}_{2.5}$ at the level of 0.01 . A good negative correlation $(r=-0.546)$ was observed between the Temp and $\mathrm{PM}_{2.5}$ levels during the study period, indicating the better dispersion of air pollutants during high-temperature conditions. Our observations were consistent with the previous findings ${ }^{28-31}$. In contrast to earlier findings ${ }^{30}$, a moderate positive correlation was observed between RH and $\mathrm{PM}_{2.5}$. This suggests that $\mathrm{PM}_{2.5}$ concentrations increased with an increase in RH. A similar relationship between particulate matter and RH has been reported earlier ${ }^{28}$.

It is noteworthy that the reductions in $\mathrm{PM}_{2.5}$ concentrations were observed even in the winter seasons, i.e. long before the lockdown was enforced. The study period taken is a transition period between winter and summer, characterized by increasing temperatures and following decline in domestic fuel usage in households (for heating purposes). As discussed earlier, the mean concentration of $\mathrm{PM}_{2.5}$ had a clear declining trend from January to April, even in 2018 and 2019 (Figure 1). About 42\%, 49\% and 63\% reduction was observed during March-April compared to preceding months (January-February) in 2018, 2019 and 2020 respectively. A decline in $\mathrm{PM}_{2.5}$ happens annually due to changes in meteorology, even in the previous years

Table 1. Pearson's correlation coefficients between $\mathrm{PM}_{2.5}$ and meteorological parameters

\begin{tabular}{lcccc}
\hline Parameters & $\mathrm{PM}_{2.5}$ & Temperature & $\begin{array}{c}\text { Relative } \\
\text { humidity }\end{array}$ & $\begin{array}{c}\text { Wind } \\
\text { speed }\end{array}$ \\
\hline $\mathrm{PM}_{2.5}$ & 1.00 & & & \\
Temperature & $-0.546^{*}$ & 1.00 & & \\
Relative humidity & $0.391 *$ & $-0.850^{*}$ & 1.00 & \\
Wind speed & $-0.382^{*}$ & $0.115^{*}$ & $-0.169^{*}$ & 1.00 \\
\hline
\end{tabular}

*Correlation is significant at 0.01 level (2-tailed). 
without lockdown (2018 and 2019). Further, this argument was supported by a good negative correlation of $\mathrm{PM}_{2.5}$ with temperature and wind speed (Table 1). Thus, $\mathrm{PM}_{2.5}$ reduction during the lockdown period compared to preceding days can also be attributed to the increasing temperature, higher wind speed and changes in atmospheric movements. Overall, the findings of the correlation analysis demonstrate the vital role of meteorology on the variations of fine particles in the atmosphere.

\section{Monthly trend of $\mathrm{PM}_{2.5}$ concentration}

To take a further look at air quality variation between months and the lockdown effect, we compare the $\mathrm{PM}_{2.5}$ concentration from January to April in 2018, 2019 and 2020. Besides, the study period was grouped into prelockdown and lockdown periods and compared. Figure 3 shows the monthly variations in $\mathrm{PM}_{2.5}$ over Delhi city in 2018, 2019 and 2020. $\mathrm{PM}_{2.5}$ concentrations trend shows a continuous reduction from January to April. The maximum pollutant concentrations occur during the winter, followed by minimum values in summer. $\mathrm{PM}_{2.5}$ concentrations decreased from $189.80 \pm 51.37$ and 136.16 \pm $37.40 \mu \mathrm{g} / \mathrm{m}^{3}$ in January-February 2018 to $97.79 \pm 19.60$ and $90.18 \pm 25.54 \mu \mathrm{g} / \mathrm{m}^{3}$ in March-April 2018. Similarly, in 2019 , monthly $\mathrm{PM}_{2.5}$ averaged $203 \pm 84 \mu \mathrm{g} / \mathrm{m}^{3}$ (54$355 \mu \mathrm{g} / \mathrm{m}^{3}$ ) in January, which is five times more than the national annual standard of $40 \mu \mathrm{g} / \mathrm{m}^{3}$. Pollution level in March and April reduced to $84 \pm 20 \mu \mathrm{g} / \mathrm{m}^{3}$ (ranged from 39 to $117 \mu \mathrm{g} / \mathrm{m}^{3}$ ) and $83 \pm 26 \mu \mathrm{g} / \mathrm{m}^{3}$ (varied from 23 to $149 \mu \mathrm{g} / \mathrm{m}^{3}$ ) respectively. Similarly, as of 2020 , monthly mean levels were found to be higher in January $\left(156.61 \pm 68.79 \mu \mathrm{g} / \mathrm{m}^{3}\right)$ and lowest in April (45.99 \pm $\left.12.31 \mu \mathrm{g} / \mathrm{m}^{3}\right)$. It is apparent from Figure 3 that $\mathrm{PM}_{2.5}$ in Delhi is substantially affected by the temporal variations. During winter, the average share of the transport sector in $\mathrm{PM}_{2.5}$ was $28 \%$. Industries and biomass burning (in houses and farming arenas) contribute to $30 \%$ and $14 \%$ respectively. While in summer, the significant portion was contributed by road and construction dust (38\%). The share of the industrial sector for the same is about $22 \%$ and transport contributes $17 \%$. Significantly high contributions due to atmospheric transport from outside of Delhi have also been observed during the summer season ${ }^{32,33}$. The winter-time concentration of $\mathrm{PM}_{2.5}$ is mostly high due to the massive emission of anthropogenic pollutants from heating, industry and traffic, and also due to the adverse weather conditions in favour of the massive accumulation of pollutants. Changes in the atmospheric circulation, while changing from winter to summer, accelerate the dispersion of pollutants; hence a declining trend of $\mathrm{PM}_{2.5}$ concentration was observed from January to April $^{6}$.

In the present study, the long-range transport effect was excluded and the concentrations during the curfew period were compared to know the effect of COVID-19 lockdown on $\mathrm{PM}_{2.5}$. The mean $\mathrm{PM}_{2.5}$ before the lockdown days (1 January-24 March) was 145 (in 2018) and 141 (in 2019) $\mu \mathrm{g} / \mathrm{m}^{3}$, whereas it was $118 \mu \mathrm{g} / \mathrm{m}^{3}$ in $2020 . \mathrm{PM}_{2.5}$ in the pre-lockdown period was about $18.62 \%$ and $16.31 \%$ lower in 2020 when compared to the same period of 2018 and 2020. This drastic reduction in PM over the years has to be investigated to get a better understanding of whether the effect is from policies and measures implemented in previous years. Likewise, 91.55, 83.54 and $43.66 \mu \mathrm{g} / \mathrm{m}^{3}$ were the average $\mathrm{PM}_{2.5}$ from 25 March to 30 April (i.e. lockdown period) for 2018-2020 respectively. About $37 \%, 41 \%$ and $63 \%$ decline during lockdown days in comparison with preceding days was observed in 2018, 2019, and 2020 respectively. Even though the temperature was slightly lower during the lockdown period in $2020\left(27.3^{\circ} \mathrm{C}\right)$ than in previous years $\left(31.5^{\circ} \mathrm{C}\right.$ in 2018 and $29.4^{\circ} \mathrm{C}$ in 2019 ), the reduction in $\mathrm{PM}_{2.5}$ was significantly higher in 2020, thus indicating the indispensable role of COVID-19 control measures and actions on the reduction of $\mathrm{PM}_{2.5}$.

\section{Spatial distribution of $P M_{2.5}$}

The spatial interpolation (IDW) method was used to study the spatial variations in $\mathrm{PM}_{2.5}$ concentration over NCT Delhi. Monthly averaged $\mathrm{PM}_{2.5}$ concentrations of 2018-2019 were taken as baseline level for comparison. Figure $4 a$ and $b$ shows the spatial and temporal distribution of $\mathrm{PM}_{2.5}$ concentrations in NCT Delhi from January to April. It is evident that no region falls under good air quality during the baseline years. Comparatively, more significant concentrations of $\mathrm{PM}_{2.5}$ were recorded in North, Northwest and central Delhi. This can be perceptible from the spatial pattern of concentration of $\mathrm{PM}_{2.5}$ in different months of 2018-2019 (Figure 4 a). Also, a similar trend was observed in the recent period (2020). However, as anticipated, after the lockdown declaration starting from 25 March 2020, $\mathrm{PM}_{2.5}$ pollution of the megacity Delhi witnessed a substantial reduction.

Figure 5 highlights the spatial pattern of variations in the concentration of the $\mathrm{PM}_{2.5}$ from January to April 2020 in comparison to the preceding years (2018-2019) for the same period. A month before the government announced the lockdown, the concentration of $\mathrm{PM}_{2.5}$ all over the city was at a comparatively high level (Figure $4 \mathrm{~b}$ ). On average, $-23.65 \%$ (ranged from $-4.92 \%$ to $-40.65 \%$ ) and $+4.40 \%$ (varied from $+48.44 \%$ to $-27.67 \%$ ) of variation was observed between baseline years and 2020 in January and February respectively. The distribution maps show systematic shifts of $\mathrm{PM}_{2.5}$ in the severely polluted North and Northwest regions of Delhi city during the COVID lockdown, with an enormous change in March and April. The percentage of variation ranged from -57.8 to -10.88 $($ mean $=-34.48 \%)$ in March, which may be attributed to 


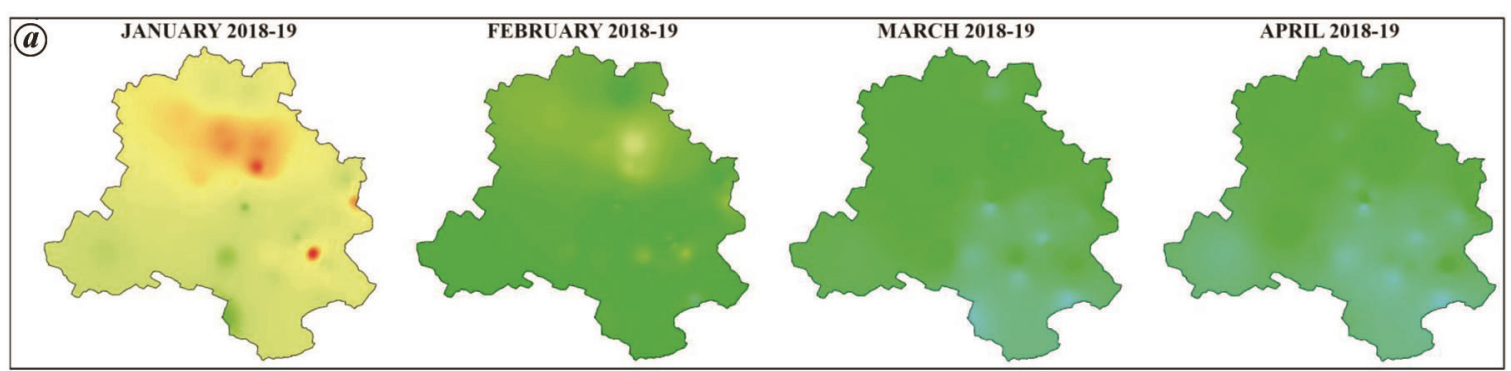

$\mathrm{PM}_{2.5}\left(\mu \mathrm{g} / \mathbf{m}^{3}\right)$

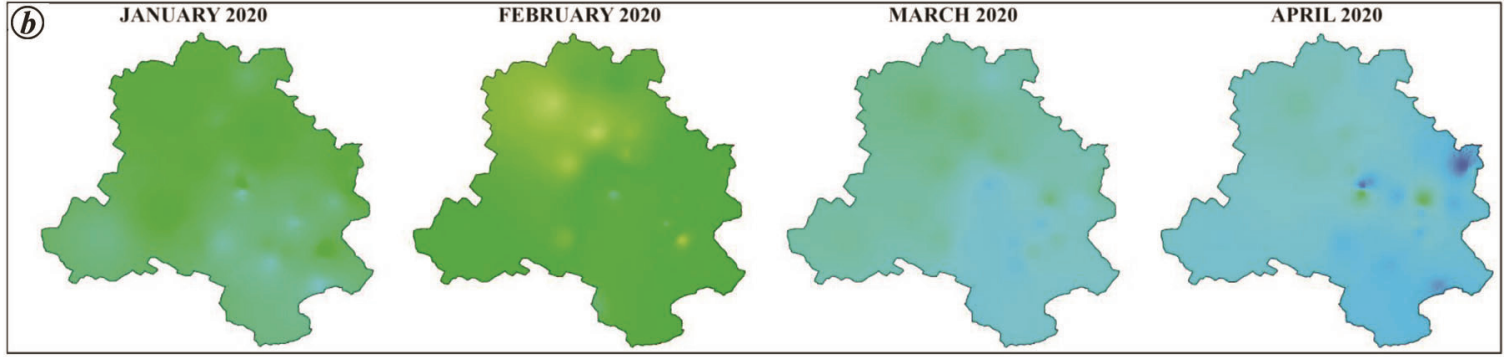

275

14

Figure 4. $\boldsymbol{a}$, Spatial distribution of fine particulate matter over NCT Delhi in 2018-19; $\boldsymbol{b}$, Spatial distribution of fine particulate matter over NCT Delhi in 2020

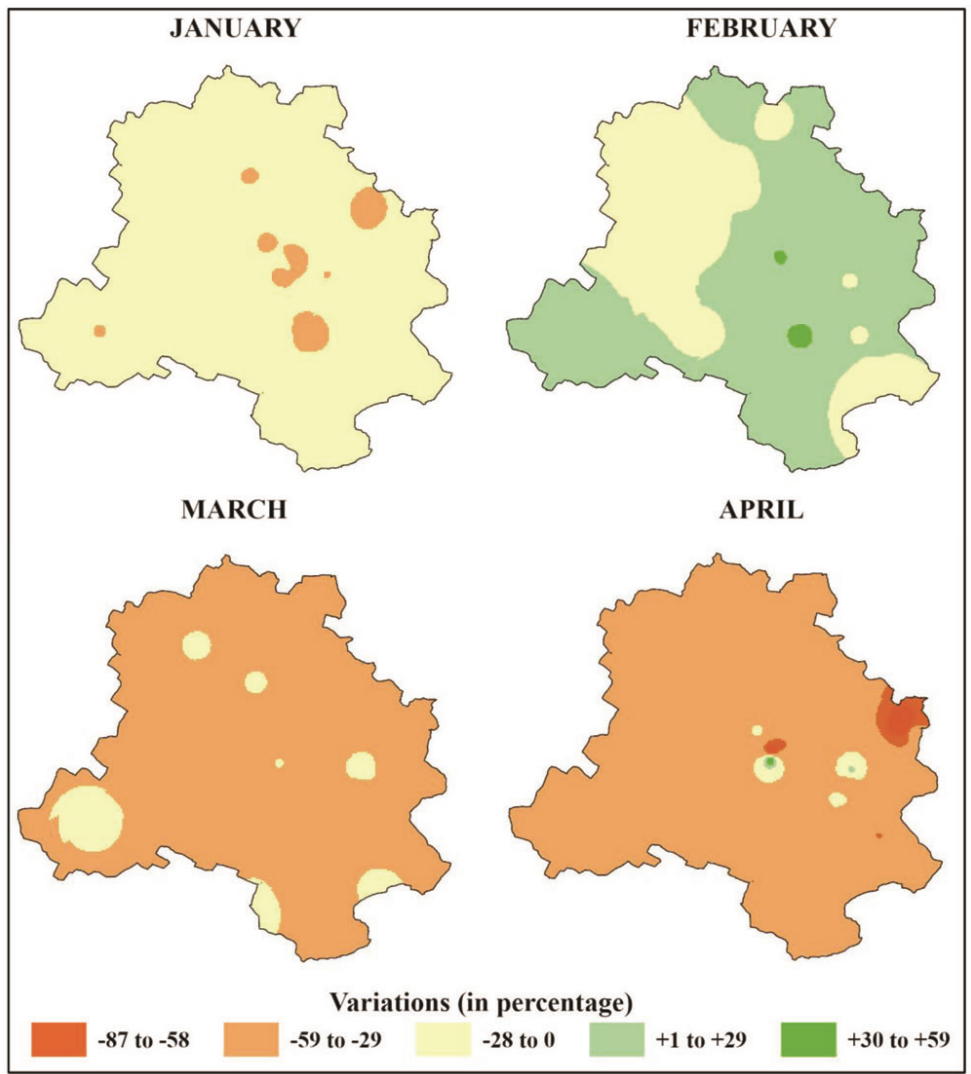

Figure 5. Variations in monthly ambient $\mathrm{PM}_{2.5}$ concentrations during 2020 in comparison with 2018-19.

lockdown implementation at the end of the month. Further extension of shutdown up to 3 May results in more reduction of $\mathrm{PM}_{2.5}$ concentration. About $43.37 \%$ of the decrease in $\mathrm{PM}_{2.5}$ level was observed in April. These findings were consistent with the observations by Mahato et $a l .{ }^{34}$. In Delhi city, concentrations of PM have reduced below the permissible limit within the four days of lockdown. The average concentration of $\mathrm{PM}_{2.5}$ has reduced by 
$39 \%$ during three weeks lockdown in comparison to the last year ${ }^{34}$. In line with previous observations, we have observed about $\sim 40 \%$ of reduction in concentrations of fine PM from 25 March to 14 April. Shrestha et al. ${ }^{35}$ found about $32.5 \%$ of reduction in $\mathrm{PM}_{10}$ concentrations over Delhi city in March 2020 compared to the past year. Similar observations were recorded recently in $\mathrm{Spain}^{36}$, Brazil $^{37}$, Italy ${ }^{38}$ and China ${ }^{39,40}$.

Overall, a significant reduction in $\mathrm{PM}_{2.5}$ occurs in Delhi city. However, it is evident from Figure 5 that reduction in $\mathrm{PM}_{2.5}$ is not equally dispersed all over the city. Meanwhile, $\mathrm{PM}_{2.5}$ level in few regions of the city exhibited a more substantial reduction, whereas the same in the ITO and Pusa remained slightly high regardless of lockdown enforcement. These increases can be attributed to the increased domestic emissions of $\mathrm{PM}_{2.5}$; because these stations were located in the residential cum commercial areas. The above findings clearly show that the decreased industrial processes and transport restrictions directly lead to the changes in $\mathrm{PM}_{2.5}$ pollution of NCT Delhi, and the effects are even higher in the broader economy, industrial and traffic intensified regions.

Even though the concentration of PM in Delhi was reduced, it was still higher in some regions than NAAQS to be considered safe. However, there is no evidence that this enhancement will endure in the long run. When India completely lifts the lockdown, energy use and emissions are expected to surpass the level before the event. The future condition of air quality of Delhi rests on by what means the Indian government will manage both economic and environmental issues together.

\section{Conclusion}

The study examined the $\mathrm{PM}_{2.5}$ pollution in NCT Delhi in the context of COVID-19 outbreak in 2020. As expected, the results indicate a significant reduction in fine particulate matter pollution due to the outbreak of COVID-19 and city lockdown. The lockdown, including restricted social contact, transport restrictions, closing a large number of industries and administrative centres, temporarily reduced levels of $\mathrm{PM}_{2.5}$, mostly in the more urbanized and traffic intensified regions. Meteorology played a vital role in this pollution reduction and the difference in the $\mathrm{PM}_{2.5}$ concentrations varied spatially. A short-term shut down can be considered as an alternate strategy to tackle the severe pollution issues in Delhi. However, this kind of measure should be implemented on a trial basis first, and its effect on other related industrial and economic sectors needs to be studied exclusively.

1. WHO ambient (outdoor) air quality database Summary results, update 2018, WHO, Geneva, Switzerland, 2018.

2. WHO global urban ambient air pollution database (update 2016), Geneva, Switzerland, 2016.
3. Balakrishnan, K. et al., The impact of air pollution on deaths, disease burden, and life expectancy across the states of India: the global burden of disease study 2017. Lancet Planetary Health, 2019, 3(1), e26-e39.

4. Todorović, I., Air pollution sharply falls worldwide on COVID-19 lockdowns, 2020; https://balkangreenenergynews.com/air-pollution-sharply-falls-worldwideon-covid-19-lockdowns/ (accessed on 27 April 2020).

5. WHO Coronavirus Disease (COVID-19) Dashboard, WHO, 2020; https:/covid19.who.int/region/amro/country/ (accessed on 7 November 2020).

6. Chen, Q. X., Huang, C. L., Yuan, Y. and Tan, H. P., Influence of COVID-19 event on air quality and their association in Mainland China. Aerosol Air Qual. Res., 2020, 20, 1541-1551.

7. Wu, X., Nethery, R. C., Sabath, B. M., Braun, D. and Dominici, F., Exposure to air pollution and COVID-19 mortality in the United States. medRxiv, 2020.

8. Gerretsen, I., How air pollution exacerbates Covid-19. BBC Future Planet, 2020; https:/www.bbc.com/future/article/20200427how-air-pollutionexacerbates-covid-19 (accessed on 28 April 2020).

9. Census of India, Population Census 2011 India, 2011; http://census2011.co.in/ (accessed on 10 May 2020).

10. Delhi Statistical Handbook, Directorate of Economics \& Statistics, Govt of NCT of Delhi, 2017, p. 379.

11. Final Economy survey of Delhi 2018-19, Planning Department, Government of NCT Delhi, 2019.

12. Kumar, P., Gulia, S., Harrison, R. M. and Khare, M., The influence of odd-even car trial on fine and coarse particles in Delhi. Environ. Pollut., 2017, 225, 20-30.

13. Chowdhury, S., Dey, S., Di Girolamo, L., Smith, K. R., Pillarisetti, A. and Lyapustin, A., Tracking ambient $\mathrm{PM}_{2.5}$ build-up in Delhi national capital region during the dry season over 15 years using a high-resolution $(1 \mathrm{~km})$ satellite aerosol dataset. Atmos. Environ., 2019, 204, 142-150.

14. Goel, R. and Pant, P., Vehicular pollution mitigation policies in Delhi. Econ. Polit. Wkly, 2016, 51(9), 41.

15. Chandra, B. P. et al., Odd-even traffic rule implementation during winter 2016 in Delhi did not reduce traffic emissions of VOCs, carbon dioxide, methane and carbon monoxide. Curr. Sci., 2018, 114(6), 000-000.

16. Central Control Room for Air Quality Management - All India. Central Pollution Control Board, Government of India, 2020; https:/app.cpcbccr.com/ccr/\#/caaqmdashboard-all/caaqm-landing/ caaqm-comparison-data

17. Technical Specifications for Continuous Ambient Air Quality Monitoring (CAAQM) Station (Real Time). Central Pollution Control Board East Arjun Nagar, Shahdara, 2019; https://jspcb. nic.in/upload/5d6f49fd8daebCAAQMSGuideline.pdf (accessed on 10 August 2020).

18. George, M. P., Sharma, S. K., Mandal, T. K. and Kotnala, R. K., Simultaneous measurements of ambient $\mathrm{NH} 3$ and its relationship with other trace gases, $\mathrm{PM}_{2.5}$ and meteorological parameters over Delhi, India. MAPAN, 2019, 34(1), 55-69.

19. Hama, S. M. et al., Four-year assessment of ambient particulate matter and trace gases in the Delhi-NCR region of India. Sustain. Cities Soc., 2020, 54, 102003.

20. Government of India issues orders prescribing lockdown for containment of COVID-19 epidemic in the country, Ministry of Home Affairs, Press Information Bureau, Government of India, 2020; https://pib.gov.in/newsite/PrintRelease.aspx?relid=200655

21. MHA Order Dt. 30.5.2020 with guidelines on extension of LD in Containment Zones and phased reopening, Ministry of Home Affairs, 2020.

22. Rahman, S. R. A., Ismail, S. N. S., Raml, M. F., Latif, M. T., Abidin, E. Z. and Praveena, S. M., The assessment of ambient air pollution trend in Klang Valley, Malaysia. World Environ., 2015, 5(1), 1-11. 
23. Zhang, G., Rui, X. and Fan, Y., Critical review of methods to estimate $\mathrm{PM}_{2.5}$ concentrations within specified research region. ISPRS Int. J. Geo-Inf., 2018, 7(9), 368.

24. Guidelines for the measurement of ambient air pollutants (NAAQS). Central Pollution Control Board, Government of India, 2009.

25. Tiwari, S. et al., Pollution concentrations in Delhi India during winter 2015-16: A case study of an odd-even vehicle strategy. Atmos. Pollut. Res., 2018, 9(6), 1137-1145.

26. Pathak, A. K., Sharma, M. and Nagar, P. K., A framework for $\mathrm{PM}_{2.5}$ constituents based (including PAHs) emission inventory and source toxicity for priority controls: a case study of Delhi, India. Chemosphere, 2020, 126971.

27. Wang, P., Guo, H., Hu, J., Kota, S. H., Ying, Q. and Zhang, H., Responses of $\mathrm{PM}_{2.5}$ and $\mathrm{O}_{3}$ concentrations to changes of meteorology and emissions in China. Sci. Total Environ., 2019, 662, 297306.

28. Tiwari, S. et al., Intra-urban variability of particulate matter $\left(\mathrm{PM}_{2.5}\right.$ and $\left.\mathrm{PM}_{10}\right)$ and its relationship with optical properties of aerosols over Delhi, India. Atmos. Res., 2015, 166, 223-232.

29. Galindo, N., Varea, M., Gil-Moltó, J., Yubero, E. and Nicolás, J., The influence of meteorology on particulate matter concentrations at an urban Mediterranean location. Water, Air, Soil Pollut., 2011, 215(1-4), 365-372.

30. Panda, S. et al., Organic and elemental carbon variation in $\mathbf{P M}_{2.5}$ over megacity Delhi and Bhubaneswar, a semi-urban coastal site in India. Natural Haz., 2016, 80(3), 1709-1728.

31. Cheng, Y. H. and Li, Y. S., Influences of traffic emissions and meteorological conditions on ambient $\mathrm{PM}_{10}$ and $\mathrm{PM}_{2.5}$ levels at a highway toll station. Aerosol Air Qual. Res., 2010, 10, 456-462.

32. Source apportionment of $\mathrm{PM}_{2.5}$ and $\mathrm{PM}_{10}$ concentrations of Delhi NCR for identification of major sources. ARAI \& TERI, New Delhi, India, 2018.

33. Marlier, M. E., Jina, A. S., Kinney, P. L. and DeFries, R. S., Extreme air pollution in global megacities. Curr. Climate Change Rep., 2016, 2(1), 15-27.
34. Mahato, S., Pal, S. and Ghosh, K. G., Effect of lockdown amid COVID-19 pandemic on air quality of the megacity Delhi, India. Sci. Total Environ., 2020, 730, 139086; doi:10.1016/ j.scitotenv.2020.139086.

35. Shrestha, A. M., Shrestha, U. B., Sharma, R., Bhattarai, S., Tran, H. N. T. and Rupakheti, M., Lockdown caused by COVID-19 pandemic reduces air pollution in cities worldwide. 2020; EarthArXiv; doi:10.31223/osf.io/edt4j.

36. Tobías, A. et al., Changes in air quality during the lockdown in Barcelona (Spain) one month into the SARS-CoV-2 epidemic. Sci. Total Environ., 2020, 726, 138540; doi:10.1016/j.scitotenv. 2020.138540.

37. Dantas, G., Siciliano, B., França, B. B., da Silva, C. M. and Arbilla, G., The impact of COVID-19 partial lockdown on the air quality of the city of Rio de Janeiro, Brazil. Sci. Total Environ., 2020, 729, 139085.

38. Raffaelli, K., Deserti, M., Stortini, M., Amorati, R., Vasconi, M. and Giovannini, G., Improving air quality in the Po Valley, Italy: Some results by the LIFE-IP PREPAIR Project. Atmosphere, 2020, 11(4), 429.

39. He, G., Pan, Y. and Tanaka, T., COVID-19, City lockdown, and air pollution: Evidence from China. medRxiv, 2020, 2020.03.29.20046649; doi:10.1101/2020.03.29.20046649.

40. Huang, X. et al., Enhanced secondary pollution offset reduction of primary emissions during COVID-19 lockdown in China. Nat. Sci. Rev., 2020; doi:10.1093/nsr/nwaa137.

ACKNOWLEDGEMENT. We thank the anonymous reviewers and editor for their valuable suggestions, which helped in improving the quality of the manuscript.

doi: $10.18520 / \mathrm{cs} / \mathrm{v} 120 / \mathrm{i} 2 / 304-312$ 